\title{
Perancangan Alat Penanggulangan Dini Bencana Banjir Berbasis Inframerah Dengan Mikrokontroller Atmega16, Pompa Air, Dan Calling
}

\author{
Eri Riana \\ Program Studi Manajemen Informatika, AMIK BSI Bekasi, Jawa Barat, Indonesia \\ Jl. Cut Mutia Raya No. 88, Margahayu, Bekasi Timur, Jawa Barat, Indonesia \\ email: eri.eea@bsi.ac.id
}

\begin{abstract}
Abstrak
Pada saat musim penghujan tiba menuntut kita untuk selalu waspada dengan adanya bencana banjir. Untuk meminimalkan kerugian yang diakibatkan oleh banjir maka perlu adanya sebuah alat yang dapat mendeteksi dan menanggulangi banjir secara otomatis. Secara umum alat pendeteksi banjir otomatis dirancang dengan menggunakan Mikrokontroler Atmega 16. Banjir akan dideteksi oleh sensor selanjutnya akan diteruskan sensor Inframerah ke mikrokontroler. Kemudian mikrokontroler Atmega 16 akan mengaktifkan buzzer relay dan sim8001. Dengan aktifnya buzzer berupa bunyi menunjukkan adanya banjir, secara otomatis relay akan menghidupkan pompa untuk menyedot air, dan sim8001 akan melakukan panggilan (calling). Dengan demikian kita dapat segera mengamankan diri dan barang-barang berharga lainnya.
\end{abstract}

Kata Kunci: Atmega16, Inframerah, Sim8001, Banjir

\section{Abstract}

At the time of the rainy season requires us to be vigilant with their floods. To minimize losses caused by floods then the need for a tool that can detect and automatically controlling the floods. In general, automatic flood detector designed using Atmega microcontroller 16. The flood is detected by sensors Infrared sensors will then be forwarded to the microcontroller. Then Atmega microcontroller 16 will activate the buzzer relay and sim8001. With its active form buzzer sounds indicate a flood, the relay will automatically turn on the pump to suck up the water, and sim8001 will make calls (calling). Thus we can immediately safeguard themselves and other valuables.

Keywords: ATmega16, Inframerah, Sim8001, Flood

\section{PENDAHULUAN}

Banjir adalah peristiwa yang terjadi ketika aliran air yang berlebihan merendam daratan. Banjir diakibatkan oleh volume air di suatu badan air seperti sungai atau danau yang meluap atau menjebol bendungan sehingga air keluar dari batasan alaminya, ukuran danau atau badan air terus berubah-ubah sesuai perubahan curah hujan dan pencairan salju musiman, namun banjir yang terjadi tidak besar kecuali jika air mencapai daerah yang dimanfaatkan manusia seperti desa, kota, dan permukiman lain. Banjir juga dapat terjadi di sungai, ketika alirannya melebihi kapasitas saluran air, terutama di kelokan sungai. Banjir sering mengakibatkan kerusakan rumah dan pertokoan yang dibangun di dataran banjir sungai alami.

Menurut Agus Muliantara, dkk (2015:31) "Berbagai cara digunakan untuk mengatasi bencana banjir yang diakibatkan oleh tingginya intensitas curah hujan. Diantaranya adalah memperbaiki irigasi, menambah titik-titik serapan air. Namun kadang kala cara yang digunakan untuk mengatasi banjir belum cukup untuk meminimalkan kerusakan yang diakibatkan oleh hujan. Meskipun saluran irigasi dan daerah resapan sudah luas, banjir masih saja terjadi. Untuk itu perlu dilakukan upaya evakuasi sebelum terjadinya banjir tersebut. Untuk itu diperlukan sebuah alat yang mampu memberikan informasi ketinggian curah hujan yang terjadi”.

Berdasarkan prakiran cuaca dari Badan Meteorologi Klimatologi dan Geofisika (BMKG) bahwa sebagian besar wilayah Indonesia berpotensi mengalami bencana banjir, baik itu banjir tinggi, menengah maupun rendah. Secara umum banjir disebabkan oleh dua faktor yaitu faktor alam dan peran manusia. Perlu diketahui bersama bahwa banjir sulit untuk dicegah akan tetapi bisa dikendalikan, untuk itu marilah bersama - sama untuk berkontribusi mencegah terjadinya bencana banjir.

\section{TEORITIS}

\subsection{Mikrokontroler}

Menurut Sumarno, dkk (2013) bahwa "Salah satu teknologi yang sering dipakai dalam pembuatan sistem berbasis teknologi adalah mikrokontroler yang memiliki banyak kelebihan diantaranya bisa bekerja otomatis, bekerja realtime 24 jam, bisa diintegrasikan dengan alat input output lain, membutuhkan daya yang rendah, tahan lama, dan lain-lain. Mikrokontroler adalah sebuah sistem mikroprosesor yang dikemas dalam sebuah IC (integrated 
circuit) yang didalamnya sudah terdapat $C P U, R O M, R A M, I / O$, Clock dan peralatan internal lainnya yang sudah saling terhubung dan terorganisasi (teramati) dengan baik oleh pabrik pembuatan mikrokontroler. Mikrokontroler digunakan untuk fungsi dan tugas yang khusus yaitu mengatur sistem, dengan kata lain mikrokontroler digunakan sebagai otak suatu sistem". Penelitian ini membahas pengontrolan sistem yang dilakukan oleh mikrokontroler atmega16 yang mempunyai input berupa sensor ultrasonik yang berfungsi sebagai pendeteksi level ketinggian air yang kemudian di proses oleh mikrokontroler atmega16 untuk mengetahui keadaan air disuatu tempat. Output yang digunakan berupa buzzer yang dapat mengeluarkan suara pertanda keadaan air sedang mencapai batas tertentu, kemudian alat ini juga menggunakan output berupa calling yang berfungsi memberikan sebuah informasi kepada handphone seseorang berupa calling pemberitahuan keadaan air saat itu. Kondisi ultrasonik akan ditampilkan melalui sms jika keadaan jarak air sudah terdeteksi oleh ultrasonik.

\subsection{Konsep dan Rangkaian Dasar Alat}

Telah dilakukan perancangan alat penanggulangan bencana banjir dini berbasis inframerah dengan mikrokontroler atmega16, pompa air, dan calling. Sistem alat ini dibangun untuk mengetahui keberadaan air pada suatu tempat secara otomatis serta dapat melakukan tindakan penyedotan air pada saat keadaan banjir sedang terjadi. Perancangan alat ini terdiri dari input berupa sensor inframerah, untuk pemproses menggunakan mikrokontroler atmega16 dengan output berupa pompa air, buzzer, dan calling yang dipadukan dengan bahasa c sebagai bahasa pemrograman. Rangkaian dasar alat penanggulangan dini bencana banjir berbasis inframerah dengan mikrokontroler atmega16, pompa air, dan calling terdiri dari beberapa komponen berupa transformator, voltage regulator, Micro 360 DC step down, kapasitor, diode, buzzer, relay, transistor, cyristal, resistor, saklar push on, header dan konektor, pcb.

\subsection{Sensor Inframerah}

Sensor Inframerah adalah radiasi elektromagnetik dari panjang gelombang lebih panjang dari pada cahaya tampak, tetapi lebih pendek dari radiasi gelombang radio. Radiasi inframerah memiliki jangkauan tiga "order" dan memiliki panjang gelombang antara $700 \mathrm{~nm}$ dan $1 \mathrm{~mm}$.

\subsection{Rangkaian Output}

\section{Buzzer}

Buzzer adalah komponen elektronika yang berfungsi mengeluarkan suara, prinsip kerja buzzer yaitu merubah getaran listrik menjadi getaran suara. Didalam buzzer terdapat kumparan yang terpasang pada diafragma dan kemudian kumparan tersebut dialiri arus sehingga menjadi electromagnetic yang bekerja untuk menarik atau mengeluarkan kumparan arus yang ada didalam buzzer. Buzzer biasa digunakan sebagai indikator (alarm) bahwa proses sedang bekerja atau proses sudah selesai pada sebuah alat.

\section{Relay}

Menurut Rusmadi (20070b:46) "Relay adalah komponen elektronik yang berfungsi untuk menghubungkan dan memutuskan suatu hubungan seperti sebuah sakelar, namun bekerjanya secara otomatis".

\section{SIM800L}

SIM800L adalah salah satu Module GSM/GPRS Serial yang dapat kita Gunakan bersama Arduino/AVR. Chip : SIM800L harus mempunyai tegangan masuk 3,7 - 4,2V (datasheet $=3,4-4,4 \mathrm{~V}$ ) dan mempunyai Frequensi QuadBand 850/900/1800/1900Mhz. Module SIM800L memiliki 12 pin header, 6 di sisi kanan dan 6 disisi kiri : NET = Antena, VCC $=+3.7-4.2 \mathrm{~V}, \mathrm{RST}=$ Reset, RXD $=$ Rx Data Serial, TXD $=$ Tx Data Serial, GND = Ground/0V, RING when call incoming, DTR, MICP = Microphone +, MICN = Microphone - , SPKP = Speaker ,$+ \mathrm{SPKN}=$ Speaker -

\subsection{Mikrokontroller ATMega 16}

Menurut Heri Andrianto (2013a:1) “ Mikrokontroler Atmega16 adalah sebuah komputer kecil (special purpose computers) di dalam satu IC yang berisi CPU, memori, timer, saluran komunikasi serial dan paralel, port input/output, ADC'. Hampir semua instruksi dieksekusi dalam satu siklus clock. Atmega16 mempunyai 32 register general purpose, timer/counter fleksibel dengan model compare, interrupt internal dan eksternal, serial UART, programmable wacthdog timer, dan mode power saving, ADC dan PMW internal. 


\section{ANALISA DAN PEMBAHASAN}

Pada hardware Perancangan Alat Penanggulangan Banjir Berbasis Inframerah Dengan Mikrokontroler, Pompa Air, dan Calling adalah menggunakan inframerah sebagai sensor pendeteksi keberadaan air dan sekaligus untuk pemberi input logic ke mikrokontroler, menggunakan mini GPS/GPRS SIM800L untuk mengirimkan Calling berupa informasi yang sedang terjadi kepada Nomor handphone pemilik (jumlah nomor handphone bisa lebih dari satu), menggunakan rangkaian atmega16 sebagai pengendali kerja untuk menjalankan semua proses, sedangkan batasan masalah pada software adalah pengisian program menggunakan CodeVision AVR dan menggunakan bahasa $\mathrm{C}$ sebagai bahasa pemrograman.

Adapun metode penelitian yang dilakukan pada perancangan ini antara lain:

a. Planning

Planning (Perencanaan) ini dimaksudkan untuk memperoleh perancangan dan realisasi simulasi pembuatan alat pendeteksi banjir otomatis. Setelah didapatkan suatu rancangan tersebut kemudian dimulai dengan perakitan, pemrograman, dan percobaan dengan menjalankan alat.

b. Desain

Membuat alur sistem yang sudah dirancang untuk mempermudah pembuatan alat yang akan dibuat termasuk diagram blok rangkaian, rangkaian sistem dan flowchart untuk mengetahui jika terjadi suatu kesalahan.

c. Testing

Melakukan pengujian secara visual serta melakukan pengujian komponen dan koneksi antar alat secara keseluruhan.

Untuk metode pengumpulan data yang dilakukan oleh penulis untuk memperoleh data dalam perancangan ini sebagai berikut:

a. Observasi

Observasi adalah mengumpulkan data secara langsung pada sebuah rangkaian yang berbasis mikrokontroler atmega16 dan cara kerja alat untuk mencari kelengkapan data-data yang dibutuhkan, dengan cara ini dapat diperoleh gambaran tentang alat.

b. Studi Pustaka

Penulis menggunakan studi pustaka dengan cara membaca dan mempelajari buku-buku dan jurnal mengenai mikrokontroller

\subsection{Skema Blok Diagram}

Dalam perancangan langkah pertama adalah membuat suatu diagram blok dari sistem yang akan dibuat, dimana setiap blok mempunyai fungsi tertentu dan gabungan dari tiap-tiap blok tersebut akan membentuk suatu sistem.

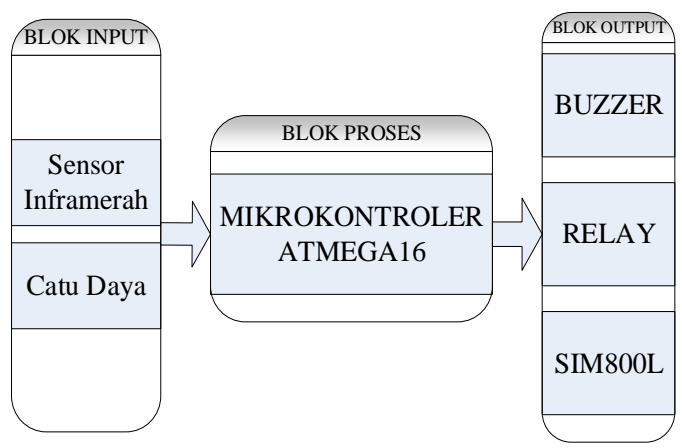

Gambar 1. Diagram Blok

Sumber : Hasil Penelitian (2018)

Berikut ini fungsi-fungsi dari blok rangkaian tersebut :

1. Blok Input

Blok input merupakan blok yang mewakili data yang masuk ke dalam sistem. Berfungsi sebagai masukan yang telah mempunyai data untuk di proses dalam blok proses. Ada dua bagian dalam blok input, yaitu:

a.Catu Daya

Catu daya berfungsi untuk memberikan supplay tegangan ke dalam blok proses dan ke dalam blok output. b.Sensor inframerah 
Sensor inframerah digunakan sebagai input untuk memberi nilai logika (signal) ke dalam mikrokontroler atmega16. Sensor ini berfungsi untuk mendeteksi adanya air, port yang digunakan untuk input adalah port PA0, PA1, dan PA2.

2. Blok Proses

Blok proses dilakukan oleh Mikrokontroler Atmega 16 yang berfungsi mengatur semua proses pengolahan data yang masuk dari komponen input yaitu sensor inframerah dan keluar dari komponen output yaitu buzzer, relay, dan sim8001.

3. Blok Output

Blok output adalah blok yang berfungsi sebagai penerima perintah dari blok proses, ada dua bagian dalam blok output sebagai penerima perintah dari blok proses, yaitu:

a. Buzzer

Buzzer adalah komponen yang berfungsi sebagai indikator berupa suara.

b. Relay

Relay berfungsi sebagai saklar tegangan AC yang bekerja untuk menghubungkan atau memutuskan arus listrik.

c. $\operatorname{Sim} 8001$

Sim8001 merupakan salah satu Module GSM/GPRS Serial yang mempunyai Frequensi QuadBand 850/900/1800/1900Mhz. difungsikan sebagai calling.

\subsection{Rangkaian Diagram}

\section{Rangkaian Input}

Inframerah yang akan memberi signal analog ke dalam mikrokontroler atmega16 dengan cara diberi cahaya dioda yang dihadapkan tepat didepan inframerah. Ada tiga port yang terhubung ke mikrokontroler atmega16 yaitu port PA0, PA1, PA2.

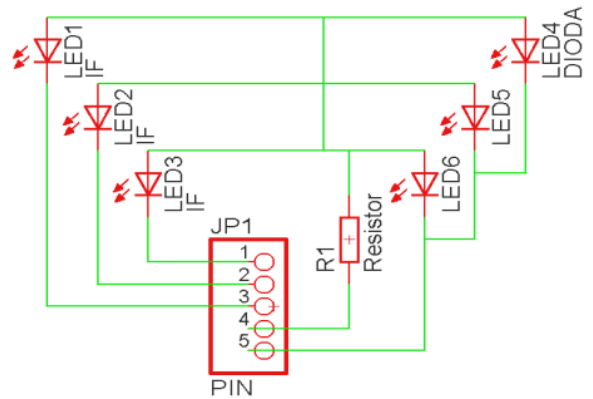

Gambar 2. Rangkaian Sensor Inframerah

Sumber : Hasil Penelitian (2018)

\section{Rangkaian Mikrokontroler}

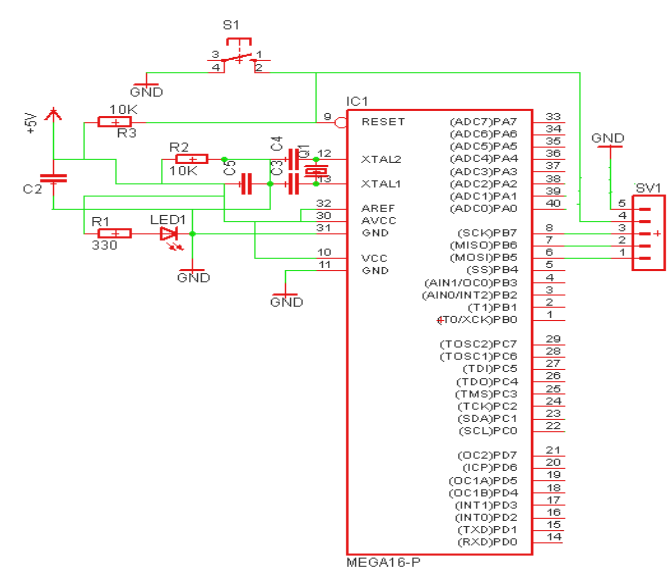

Gambar 3. Rangkaian Sistem Mikrokontroler ATMega16

Sumber : Hasil Penelitian (2018) 


\section{Rangkaian Output}

a. Buzzer

Pada rangkaian buzzer ini dipasang sebuah komponen transistor berfungsi sebagai penguat tegangan untuk menghidupkan buzzer agar lebih kencang. Fungsi buzzer disini sebagai sensor mendeteksi adanya banjir yang mengeluarkan bunyi dan terhubung ke port PC1 pada Mikrokontroler Atmega 16.

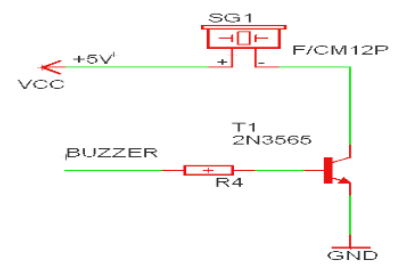

Gambar 4. Rangkaian Buzzer

Sumber : Hasil Penelitian (2018)

b. Relay

Pada rangkaian relay ini berfungsi sebagai keluaran yang berupa tegangan yang digunakan untuk menghidupkan pompa pada saat sensor mendeteksi adanya banjir yang terhubung ke port PC0 pada Mikrokontroler Atmega 16.

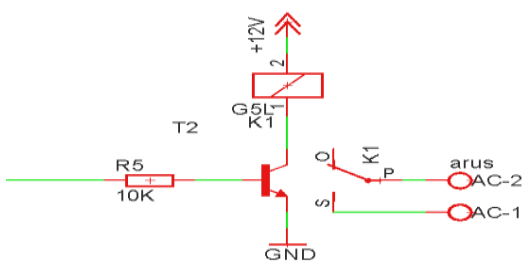

Gambar 5. Rangkaian Relay

Sumber : Hasil Penelitian (2018)

c. SIM800L

Sim8001 akan berfungsi ketika mendapatkan tegangan 4,2 volt dan yang bisa mengatur tegangan 4,2 volt hanya menggunakan komponen step down dimana tegangan pada umumnya hanya menghasilkan jumlah genap. Sim8001 terhubung mikrokontroler atmega16 PD0 dan PD1 yang akan digunakan sebagai output pemanggil telpon (calling).

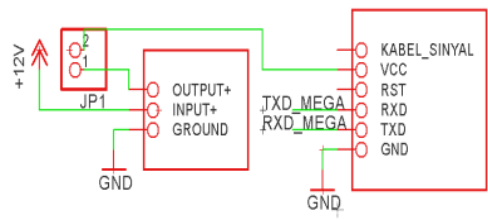

Gambar 6. Rangkaian Step Down dan Sim8001

Sumber : Hasil Penelitian (2018)

d. Rangkaian Catu Daya

Tegangan yang digunakan 220 Volt AC yang di hasilkan dari listrik PLN kemudian masuk ke dalam transformator untuk diturunkan menjadi 12 Volt AC. Pada rangkaian ini terdapat dioda yang berfungsi mengubah arus 12 Volt AC menjadi 12 Volt DC. IC Regulator 7805 berfungsi untuk membatasi tegangan 12 Volt DC menjadi 5 Volt DC. Kapasitor elektrolit sebagai penyimpan tegangan sementara berfungsi untuk menstabilkan tegangan.

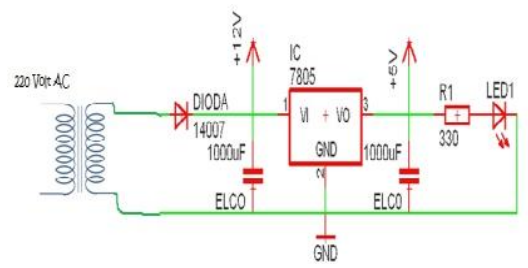

Gambar 7. Rangkaian Catu Daya

Sumber : Hasil Penelitian (2018)

Eri Riana | http://ejurnal.stmik-budidarma.ac.id/index.php/mib | Page | 103 
e. Rangkaian Keseluruhan

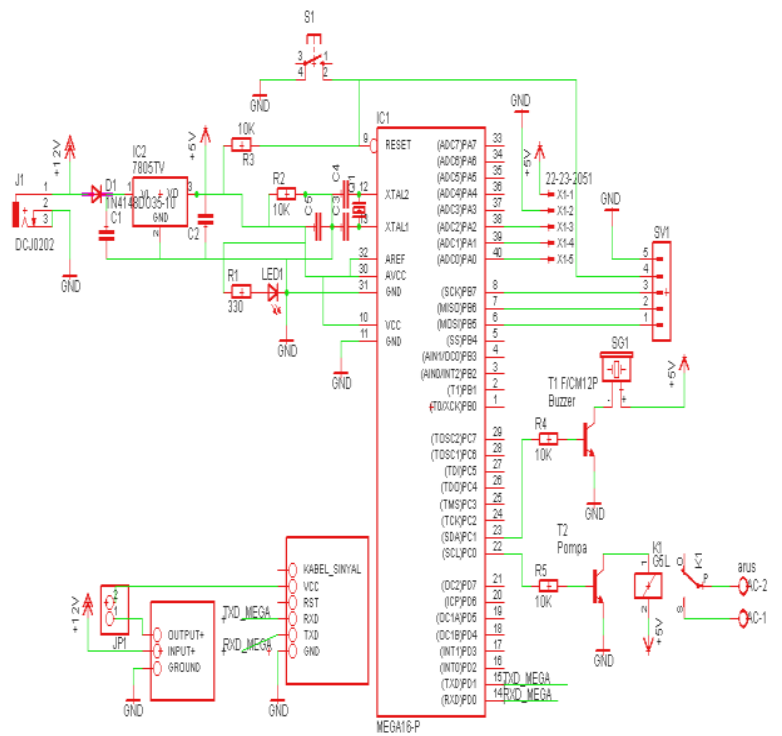

Gambar 8. Rangkaian Alat Keseluruhan Sumber : Hasil Penelitian (2018)

\subsection{Flowchart Program}

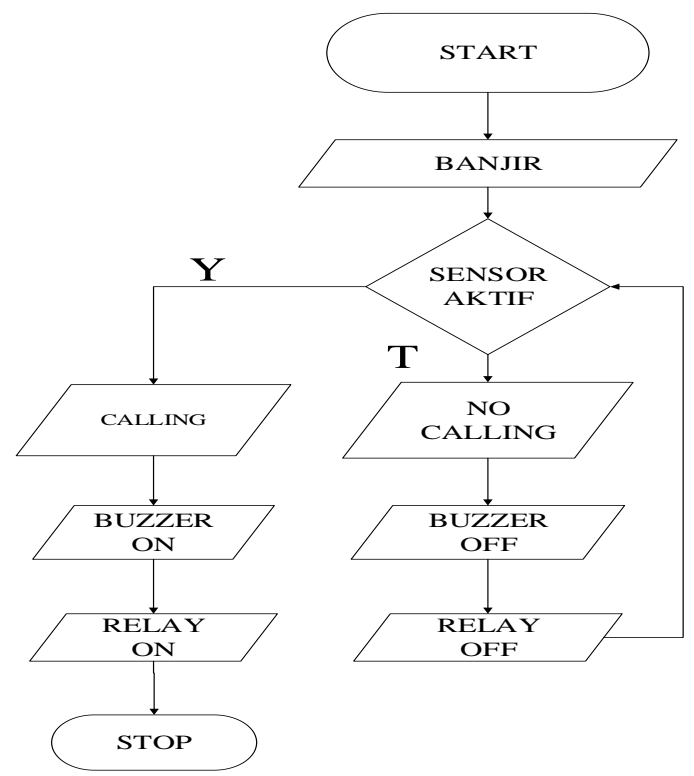

Gambar 9. Flowchart Program Sumber : Hasil Penelitian (2018)

\subsection{Kontruksi (Code)}

Berikut adalah langkah-langkah konstruksi sistem (code) dalam pembuatan sistem penanggulangan dini bencana banjir berbasis inframerah, yaitu :

\#include <mega16.h>

\#include <delay.h>

\#include <stdio.h>

\#define INFRA1 PINA.0

\#define INFRA2 PINA.1

\#define INFRA3 PINA.2

\#define RELAYIO DDRC.0

Eri Riana | http://ejurnal.stmik-budidarma.ac.id/index.php/mib | Page | 104 
\#define RELAYHL PORTC.0

\#define BUZZERIO DDRC. 1

\#define BUZZERHL POTRC.1

Unsigned int $\mathrm{i}, \mathrm{j}$;

Char*kalimat;

$\{$ RELAYHL=1;delay_ms(300); $\}$ delay_ms(500); $\}$

void relay_aktif(int status_relay)

$\{$ if(status_relay $>0)\{$ RELAYHL $=1 ;\} \operatorname{else}\{$ RELAYHL $=0 ;\}\}$

char *baca_teks(int jml_teks) $\{$ char a,*nilai;

for $\left(\mathrm{a}=0 ; \mathrm{a}<\mathrm{jml} \_\right.$teks;a++) $\{$nilai[a]=getchar();\}return nilai; $\}$

char *kata2;

$\{\operatorname{kata} 2[\mathrm{a}]=\operatorname{getchar}() ;\}\}$

void kosongkan()

$\{$ char $\mathrm{a} ;$ for $(\mathrm{a}=0 ; \mathrm{a}<255 ; \mathrm{a}++)\{\operatorname{kata} 2[\mathrm{a}]=0 ;\}\}$

void main (void)

\{

$\{$ char status_input $=0$;

PORTA $=0 \times$ FF $; D D R A=0 \times 00$;

$\mathrm{PORTB}=0 \mathrm{x} 00 ; \mathrm{DDRB}=0 \times 00$;

$\mathrm{PORTC}=0 \times 00 ; \mathrm{DDRC}=0 \times 00$;

PORTD $=0 \times 00 ; D D R D=0 \times 00$;

$\mathrm{UCSRA}=0 \times 00 ; \mathrm{UCSRB}=0 \times 18$;

$\mathrm{UCSRC}=0 \times \mathrm{x} 86 ; \mathrm{UBRRH}=0 \times 00$;

UBRRL $=0 \times 47$;

ACSR=0x80;

$\mathrm{BUZZERIO}=1$;

BUZZERHL $=0$;

RELAYIO $=1$;

RELAYHL $=0$;

delay_ms(1000);

delay_ms(1000);

delay_ms(1000);

While(1)

\{

puts("ATE0");

putchar(0x0D);

delay_ms(1000);

if $($ INFRA $1==0)\{$ status_input $=1$;

relay_aktif(1);

BUZZERHL=1;

delay_ms(1000);

BUZZERHL=0;

delay_ms(1000);

puts("ATH");

putchar(0x0D);

delay_ms(2000);

puts("ATD0895332850621;");

putchar(0x0D);

delay_ms(3000);

\}

else if(INFRA2 $==0)\{$ status_input $=1$;

relay_aktif(2);

BUZZERHL=1;

delay_ms(1000);

else if(INFRA3 $==0)\{$ status_input $=1$;

relay_aktif(3);

BUZZERHL=1;

delay_ms(1000); 


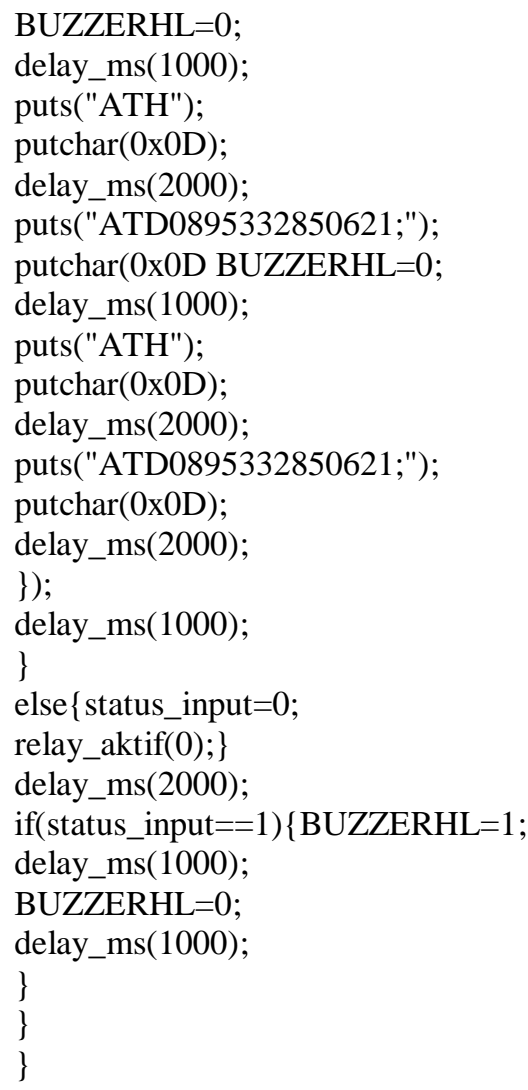

\subsection{Permasalahan Pengujian}

Terjadi sebuah kerusakan pada saat alat dihidupkan, tegangan masuk untuk menghidupkan sim8001 terlalu besar, sim8001 meledak dan menjadi rusak, sim8001 sangat rentan dalam masalah tegangan, harus stabil dan tidak boleh terpengaruh oleh keadaan listrik yang naik turun.

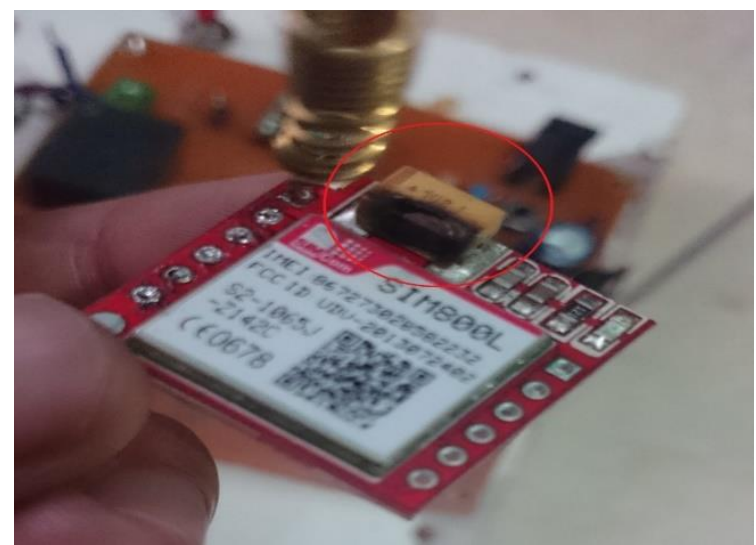

Gambar 10. Sim800I Rusak

Sumber : Hasil Penelitian (2018)

\subsection{Alternatif Pemecahan Masalah}

Agar tidak terjadi kerusakan kembali pada sim8001 maka sebelum arus masuk ke dalam sim8001 harus dipasang sebuah komponen yang mampu mengatur tegangan sesuai kebutuhan. Tegangan yang diperlukan adalah 4,2 volt, lebih dari nilai itu atau kurang dari nilai itu sim8001 tidak akan berfungsi sebagai mana fungsinya. Tegangan yang dikeluarkan dari catu daya bernilai 5 volt, itu artinya masih terlalu besar untuk menghidupkan sim8001. Jenis voltage regulator yang sudah digunakan masih kurang rendah untuk bisa menghidupkan sim8001. Voltage step down mampu mengatur tegangan yang diperlukan dengan cara mengatur putaran pada rangkaian stepdown tersebut. Berikut cara mengatur tegangan menggunakan komponen step down : 


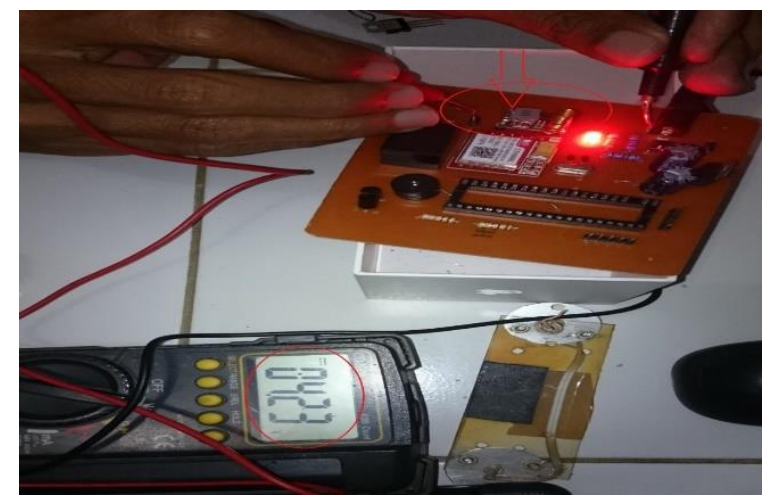

Gambar 11. Cara Mengukur Tegangan Sumber : Hasil Penelitian (2018)

\subsection{Tujuan dan Langkah Pengujian}

Pengujian dilakukan untuk mengetahui fungsi alat sudah berfungsi dengan baik atau belum berfungsi secara maksimal. Pengujian ini meliputi pengujian setiap blok maupun pengujian secara keseluruhan, pengujian setiap blok dilakukan untuk mempermudah analisis apabila alat tidak bekerja sesuai dengan perencanaan.

Langkah-langkah pengujian terhadap alat penanggulangan dini bencana banjir berbasis inframerah dengan mikrokontroler atmega16, pompa air, dan calling ini dilakukan dengan cara menghidupkan alat dan mensimulasikan sesuai fungsinya.

\section{HASIL PENGUJIAN}

\subsection{Pengujian Catu Daya}

Pengujian rangkaian catu daya bertujuan untuk memastikan bahwa tegangan dan arus listrik yang terdapat pada alat penanggulangan dini bencana banjir berbasis inframerah dengan mikrokontroler atmega16, pompa air, dan calling sesuai dengan kapasitas dan kebutuhan yang diperlukan komponen. Pengujian dapat dilakukan dengan cara mengukur arus yang keluar dengan menggunakan alat ukur avo meter. Tegangan yang dibutuhkan alat adalah 12 volt DC dan 5 volt DC.

Tabel 1. Pengujian rangkaian catu daya

\begin{tabular}{llll}
\hline No & $\begin{array}{l}\text { Masukan } \\
\text { (Volt) }\end{array}$ & $\begin{array}{l}\text { Catu } \\
\text { (Volt) }\end{array}$ & $\begin{array}{l}\text { Keluaran } \\
\text { (Volt) }\end{array}$ \\
\hline 1 & 220 Volt AC & $\begin{array}{l}\text { 12 Volt DC } \\
\text { 12 volt DC }\end{array}$ \\
2 & 12 volt DC & 5 Volt DC & 5 volt DC \\
\hline
\end{tabular}

\subsection{Pengujian Input}

Tabel 2. Pengujian input

\begin{tabular}{lllll}
\hline No & Kondisi Sensor & Buzzer & Relay & Sim800I \\
\hline 1 & Terhalang & off & off & Stay \\
2 & Tidak Terhalang & on & on & Calling \\
\hline
\end{tabular}

\subsection{Pengujian Proses}

Proses utama pada perancangan alat penanggulangan dini bencana banjir berbasis inframerah dengan mikrokontroler atmega16, pompa air, dan calling merupakan pengendali jalur input dan output. Pengendali yang dimaksud adalah pengendalian sensor inframerah yang akan diproses oleh mikrokontroler atmega16 untuk memberikan signal input yang diproses menjadi perintah keluaran (output).

\subsection{Pengujian Output}

Pengujian output pada perancangan alat penanggulangan dini bencana banjir berbasis inframerah dengan mikrokontroler atmega16, pompa air, dan calling, berupa buzzer, relay, dan sim8001 yang dapat berfungsi apabila sensor inframerah dalam keadaan on. 


\subsection{PCB Layout}

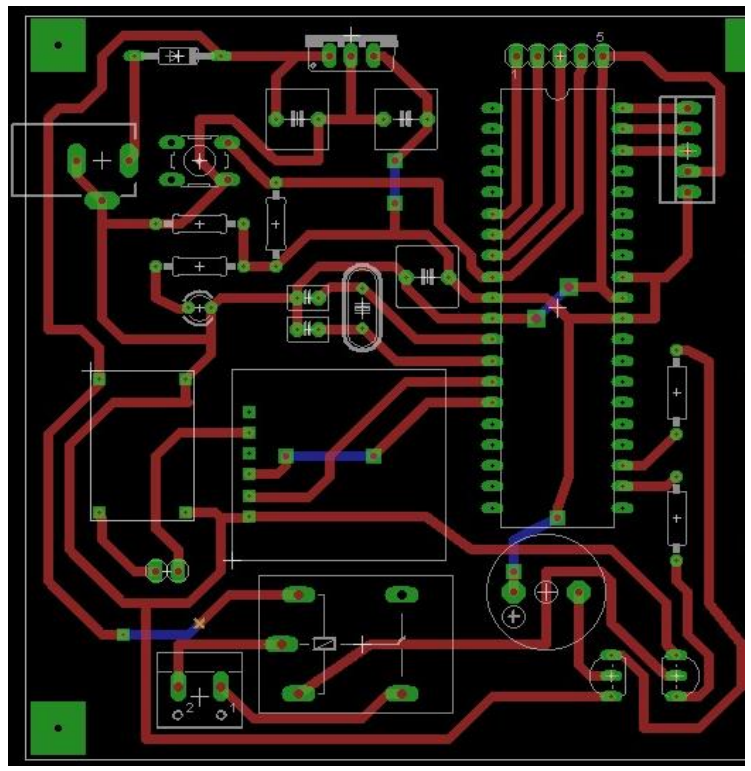

Gambar 12. PCB Layout Sumber : Hasil Penelitian (2018)

\subsection{Daftar Komponen dan Harga}

Tabel 3. Daftar Komponen dan Harga

\begin{tabular}{llll}
\hline No & Nama Komponen & Jumlah & Harga \\
\hline 1 & Mikrokontroler & 1 & Rp. 41.000 \\
& Atmega 16 & & \\
2 & Resistor 10K & 2 & Rp. 200 \\
3 & Resistor 1K & 2 & Rp. 200 \\
4 & Resistor 330 ohm & 1 & Rp. 100 \\
5 & Resistor 120 ohm & 1 & Rp. 100 \\
6 & Kapasitor 22 nF & 2 & Rp. 500 \\
7 & Elco 1000 $\mu \mathrm{F} \mathrm{16} \mathrm{V}$ & 2 & Rp. 6.000 \\
8 & IC Regulator 7805 & 1 & Rp. 3.000 \\
9 & X-TAL 11,5 Mhz & 1 & Rp. 2.000 \\
10 & Transistor D400 & 2 & Rp. 5.000 \\
11 & Relay & 1 & Rp. 6.000 \\
12 & Buzzer 5V & 1 & Rp. 3.000 \\
13 & LED & 1 & Rp. 1.000 \\
14 & Push Button & 2 & Rp. 4.000 \\
15 & Sensor Inframerah & 3 & Rp. 6.000 \\
16 & Sim8001 & 1 & Rp. 120.000 \\
17 & Kartu Perdana & 1 & Rp. 30.000 \\
18 & Socket IC 40 kaki & 1 & Rp. 4.000 \\
19 & Papan PCB & 1 & Rp. 5.000 \\
20 & Kabel Listrik & 1 & Rp. 6.000 \\
21 & Pin Head & 1 & Rp. 5.000 \\
22 & Swicth Toggle & 1 & Rp. 3.000 \\
23 & Pompa Air & 1 & Rp. 35.000 \\
24 & Transformator & 1 & Rp. 20.000 \\
& 500 mA & & \\
25 & Connector wago & 1 & Rp. 2.000 \\
Total Harga & Ferit Clorit & 1 & Rp. 3.000 \\
\hline & & & Rp. 311.100 \\
\hline
\end{tabular}

Eri Riana | http://ejurnal.stmik-budidarma.ac.id/index.php/mib | Page | 108 


\subsection{Photo Alat}

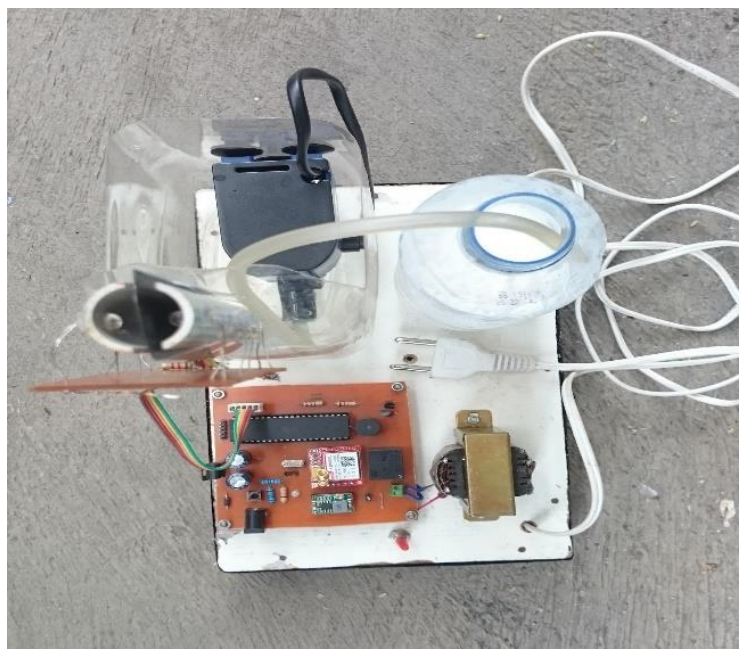

Gambar 13. Photo Alat

Sumber : Hasil Penelitian (2018)

\section{KESIMPULAN}

Setelah melakukan perancangan alat, maka kesimpulan yang dapat penulis simpulkan sebagai berikut:

1. Sensor inframerah mampu memberikan signal ke dalam mikrokontroler atmega16 sehingga menghasilkan signal output yang dapat diproses oleh komponen alat.

2. Mikrokontroler atmega16 dengan 40 pin mampu bekerja dengan baik pada rangkaian penanggulangan dini bencana banjir berbasis inframerah dengan mikrokontroler atmega16, pompa air, dan calling dengan memanfaatkan fasilitas ACD melalui input port A0 yang dihubungkan dengan sensor inframerah, kemudian memanfaatkan pengendalian output port $\mathrm{C} 0$ yang disambungkan dengan relay dan port $\mathrm{C} 1$ disambungkan dengan buzzer. Rangkaian alat ini memanfaatkan serial komunikasi yang terdapat pada mikrokontroler atmega16 melalui pin TXD dan RXD pada port D0 dan port D1.

3. Rangkaian alat penanggulangan dini bencana banjir berbasis inframerah dengan mikrokontroler atmega16, pompa air, dan calling dapat bekerja dengan baik, dimana pompa air, buzzer, dan calling berfungsi saat inframerah dalam keadaan on.

4. Alat bisa dimanfaatkan dalam keadaan banjir dini, dapat memberikan pertolongan pertama pada saat banjir, agar korban banjir bisa melakukan penyelamatan diri sebelum banjir menggenangi rumah.

\section{REFERENCES}

Andrianto Heri. 2008. "PEMOGRAMAN MIKROKONTROLER ATMEGA 16”.Bandung : Informatika Bandung. Andrianto Heri. 2013. "PEMOGRAMAN MIKROKONTROLER ATMEGA 16".Bandung : Informatika Bandung. Chandra, Arifianto. 2010. “JAGO ELEKTRONIKA".Surabaya : PT.Kawan Pustaka.

Muliantara, Agus, Ngurah Agus Sanjaya ER, Made Widiartha. Perancangan Alat Ukur Ketinggian Curah Hujan Otomatis Berbasis Mikrokontroler. ISSN 1979-5661.Fakultas MIPA: Jurnal Ilmiah Ilmu Komputer Universitas Udayana Vol.8, No.2, September 2015. Rusmadi Dedi. 2007. "BELAJAR RANGKAIAN ELEKTRONIKA TANPA GURU”.Bandung : Del Fajar Utama.

Sumarno, Beni Irawan, dan Yulrio Brianorman. 2013. Sistem Peringatan Dini Bencana Banjir Berbasis Mikrokontroler Atmega 16 Dengan Buzzer Dan Short Message Service (SMS). ISSN: 2338-493x. Pontianak: Jurnal Coding Sistem Komputer Universitas Tanjungpura Vol. 01, No.1 (2013) 30-39

Utomo, Bambang Tri Wahyu dan Hasan Saifudi 2014. Prototiping Sistem Monitoring Ketinggian Air Dan Pengendalian Pintu Air Pada Jaringan Irigasi Berbasis Microkontroler Atmega16 Dengan Menggunakan Short Message Service (SMS). Malang: Jurnal Ilmiah Teknologi dan Informasi ASIA Vol.8, No 1, Februari 2014

Simarmata, J. (2010). Rekayasa Perangkat Lunak. Yogyakarta: Andi. 